\title{
Effects of hyperbaric oxygen therapy on patients with spinal cord injury: A systematic review and meta-analysis of Randomized Controlled Trials
}

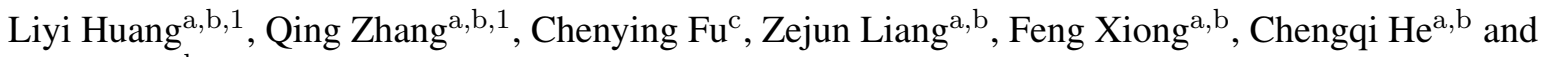 \\ Quan Wei ${ }^{\mathrm{a}, \mathrm{b}, *}$ \\ ${ }^{\mathrm{a}}$ Department of Rehabilitation Medicine Center, West China Hospital, Sichuan University, Chengdu, Sichuan, China \\ ${ }^{\mathrm{b}}$ Key Laboratory of Rehabilitation Medicine in Sichuan Province, Chengdu, Sichuan, China \\ ${ }^{\mathrm{c}}$ State Key Laboratory of Biotherapy, West China Hospital, Sichuan University, Chengdu, Sichuan, China
}

Received 1 June 2020

Accepted 4 December 2020

\begin{abstract}
.
BACKGROUND: The effects of hyperbaric oxygen therapy (HBO) for spinal cord injury (SCI) are controversial.

OBJECTIVE: The purpose of this study was to evaluate the effects of HBO therapy on motor function, sensory function, and psychology after SCI.

METHOD: We searched the following databases: Medline, Embase, PubMed, Ovid, Cochrane library, China National Knowledge Infrastructure (CNKI), Wan Fang, and VIP up to May 2020. We included Randomized Controlled Trials (RCTs) which investigated patients with SCI received HBO during hospitalization. Motor function, sensory function, and psychology status were measured by commonly used scales including American Spinal Injury Association (ASIA) motor score, Modified Barthel Index (MBI), ASIA sensory score, Hamilton Depression Scale (HAMD), and Hamilton Anxiety Scale (HAMA). We performed a meta-analysis by calculating mean difference (MD) to determine the effect of $\mathrm{HBO}$ on three levels of function on patients with SCI. We evaluated heterogeneity by $\mathrm{I}^{2}$ test, and $\mathrm{I}^{2}>50 \%$ was significant.

RESULTS: A total of 1746 studies were identified initially, and 11 studies were included, involving 875 participants. HBO therapy significantly improved the ASIA motor score (MD 15.84, 95\% CI 9.04 to $22.64, \mathrm{I}^{2}=87 \%$ ). Six trails suggested that HBO therapy statistically promoted ASIA sensory score (MD 66.30, 95\% CI 53.44 to $79.16, \mathrm{I}^{2}=95 \%$ ). The other four trails suggested that HBO therapy statistically increased the light touch score (MD 9.27, 95\% CI 3.89 to $14.65, \mathrm{I}^{2}=91 \%$ ) and needling score (MD $10.01,95 \%$ CI 8.60 to $11.43, \mathrm{I}^{2}=95 \%$ ), respectively. HBO therapy was implicated in the significant improvement of MBI (MD $13.80,95 \%$ CI 10.65 to $16.94, \mathrm{I}^{2}=0 \%$ ). HBO therapy also decreased the HAMA (MD $-2.37,95 \% \mathrm{CI}-2.72$ to $-2.02, \mathrm{I}^{2}=0 \%$ ) and HAMD (MD $-3.74,95 \% \mathrm{CI}-5.82$ to $-1.65, \mathrm{I}^{2}=90 \%$ ).
\end{abstract}

CONCLUSIONS: HBO therapy may improve motor function, sensory function and psychology after SCI compared to conventional treatments. More high-quality, large sample size RCTs are needed to support these perspectives.

Keywords: Spinal cord injury (SCI), hyperbaric oxygen (HBO), ASIA, motor function, sensory function, psychology, depression, anxiety, activities of daily living, meta-analysis

\footnotetext{
${ }^{1}$ These authors contributed equally to this work.

*Corresponding author: Quan Wei, Department of Rehabilitation Medicine Center, West China Hospital, Sichuan University, Chengdu, Sichuan, China. E-mail: weiquan@scu.edu.cn.
}

\section{Introduction}

Spinal cord injury (SCI) is usually caused by vehicle accidents, accidental falls, tumor, infection, and other traumatic events [1], which refers to various dysfunc- 
tions involving motor, sensory and sphincter dysfunction, abnormal muscle tone and pathological reflex, and other corresponding changes in the injury segments. Severe SCI may lead to paraplegia or tetraplegia ultimately. After SCI, two pathological progressions of the spine would occur: primary injuries and secondary injuries. First, for primary injuries, plentiful neuronal and glial cells go through apoptosis and axonal membrane damage. Then, for secondary injuries, astrocytes and microglia activation, glial scar formation and inflammatory response [2]. It is reported that 3 million people suffer from SCI, and there are 16-40/100,000,000 new cases in developed countries and 34.3-60/100,000,000 new cases in China $[3,4]$. However, the treatment effects of surgery and drugs are not very satisfactory. Many patients still have a very poor prognosis and low quality of life after receiving spinal decompression surgery, neurotrophic drugs, or corticosteroids. Hyperbaric oxygen therapy (HBO) is used for hypoxic diseases by suppling pure oxygen or high concentration oxygen with a mask or in an environment with over 1 atmosphere pressure. The pathological change such as tissue edema, neuro-necrosis and blood-spinal barrier disorder, are all related to the overactive inflammatory response in the injured spinal cord [6,7]. HBO may inhibit the production of inflammatory factors and promote the repair and regeneration of neurons [8]. Meanwhile, studies have shown that HBO may have many other functions including relieving hypoxia, protecting surrounding tissues, inhibiting apoptosis by control of caspase-3 expression, reducing mitochondrial dysfunction in the SCI area, and reducing bleeding area and edema [9].

Holbach et al. first found that HBO therapy could improve the postoperative dysfunction in patients with traumatic SCI [5]. Although the application of HBO therapy in traumatic SCI has a long history, the therapeutic effects of HBO therapy on SCI are controversial. To identify the effects of HBO therapy on motor function, sensory function, and psychological status in SCI patients, we summarized Randomized Controlled Trials (RCTs) of patients with SCI receiving $\mathrm{HBO}$ published up to May 2020.

\section{Method}

This meta-analysis was performed on the basis of the Preferred Reporting Items for Systematic Reviews and Meta-Analyses (PRISMA) guidelines [10] (Table S1).

\subsection{Search strategy}

We selected the following databases and search en- gines for retrieval: Medline, Embase, PubMed, Ovid, Cochrane library, CNKI, Wan Fang and VIP. Search strategy: (Spinal cord injury OR spinal cord injuries OR spinal cord trauma OR spinal cord traumas OR spinal cord transection OR spinal cord transections OR spinal cord laceration OR spinal cord lacerations OR spinal cord contusion OR spinal cord contusions) AND (hyperbaric oxygenations OR hyperbaric oxygen therapy OR hyperbaric oxygen therapies). The references of previous systematic reviews were also thoroughly screened to identify potential relevant articles.

\subsection{Study selection}

Studies were included if they met the following criteria: (1) RCT; (2) participants with SCI confirmed by computed tomography (CT) or magnetic resonance imaging (MRI); (3) interventions were HBO, including oxygen mask and hyperbaric oxygen chamber; (4) the study provided at least one of the following clinical outcomes: American Spinal Injury Association (ASIA) motor score [11], ASIA sensory score [11], Hamilton Depression Scale (HAMD) [12], Hamilton Anxiety Scale (HAMA) [12], or Modified Barthel Index (MBI) [13]. Studies in languages other than English or Chinese were excluded. Two independent researchers excluded unmatched studies by reading all titles and abstracts after duplicate removal. Then researchers downloaded the full text of the remaining articles and conducted further screening in accordance with the inclusion criteria. Two researchers discussed and decided when disagreements arose. When necessary, a third researcher participated in the selection progress.

\subsection{Data extraction}

Data of the included studies were extracted using a preset standard form (author, year of publication, number of patients, age and gender of patients, clinical characteristics, details of treatment and control, and outcomes). We contacted the authors if there was incomplete or uncertain information in the studies. Data of Sun was estimated from graphic presentation.

\subsection{Assessment of bias risk}

Bias risk was independently assessed by two researchers using the Cochrane Collaboration risk of bias tool, including random sequence generation, allocation concealment, blinding of participants and personal, blinding of outcome assessment, incomplete outcome 


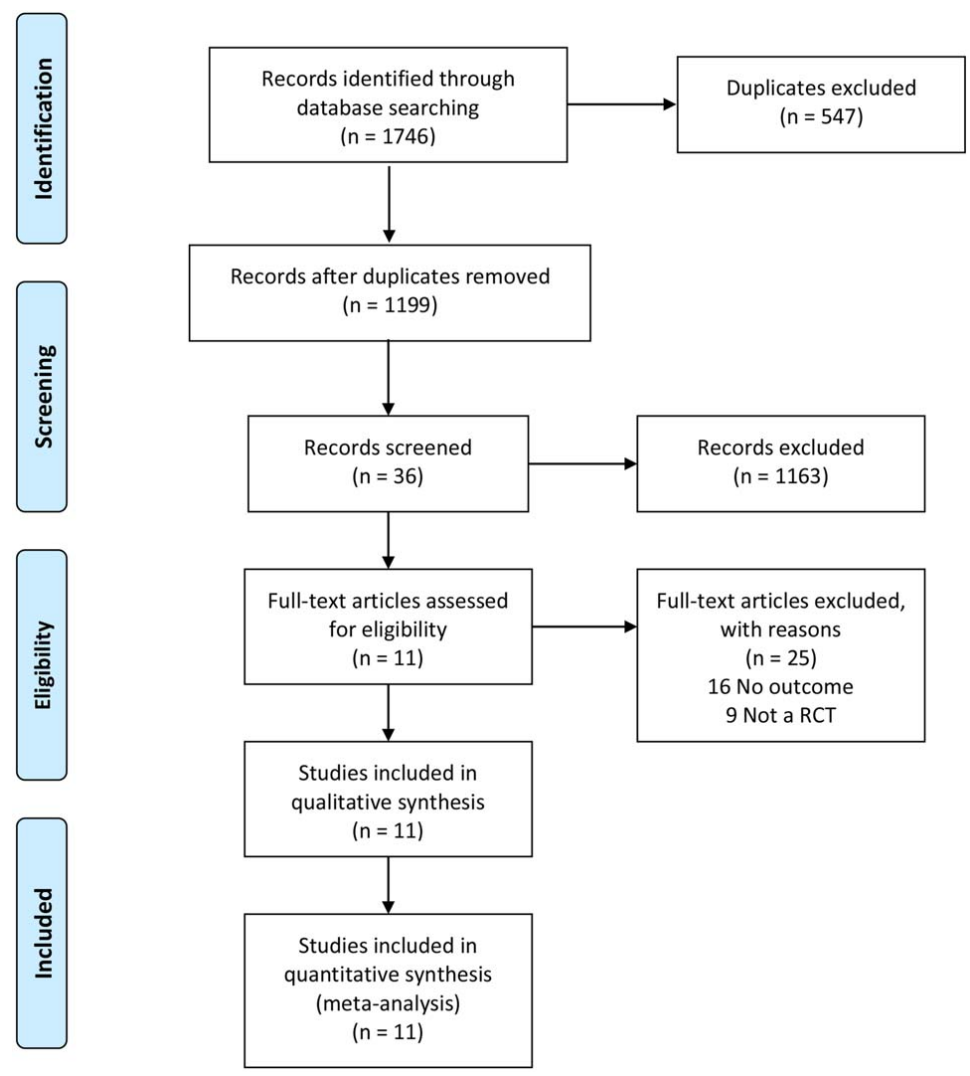

Fig. 1. Flowchart of the study selection.

data, selective reporting and other bias. Two researchers would discuss and decide when disagreements arose. If necessary, a third researcher would participate in the assessment progress.

\subsection{Outcome measures}

The primary outcomes were motor function and sensory function of patients, ASIA motor score, MBI, ASIA sensory score, HAMD and HAMA, which were measured by ASIA motor score and ASIA sensory score (light touch/needling), respectively. ASIA motor score evaluated 10 representative muscles and the bilateral total score is 100. ASIA sensory score includes light touch and needling of 28 representative sensory flat. Bilateral total score of touch and needling is 224 . A higher score represents better motor function/sensory function.

The secondary outcomes were activity of daily living (ADL) and psychological status. ADL was measured by MBI. Personal hygiene, bathing self, feeding, toilet, stair climbing, dressing, bowel control, bladder control, ambulation, or wheelchair, chair/bed transfers were taken into account. $0 \sim 24$ means total dependency needs, $25 \sim 49$ means severe dependency needs, $50 \sim$ 74 means moderate dependency needs, $75 \sim 90$ means mild dependency needs and $91 \sim 99$ means minimal dependency needs.

Psychological status was assessed by the level of depression and anxiety. Depression was measured by HAMD. A score less than 7 means that there is no depression symptom. Anxiety was measured by HAMA. HAMA includes 14 assessment items and the total score is 56. No anxiety symptoms are present when the score is less than 7. The comparison groups were experimental groups (received HBO and conventional therapy) and control groups (received conventional therapy only).

\subsection{Statistical analyses}

Statistical analyses were performed by RevMan 5.3 (The Cochrane Collaboration) and Stata 15. We calculated mean difference (MD) and corresponding 95\% confidence intervals (CI). A $P$ value lower than 0.05 indicated significant difference. Heterogeneity was eval- 
uated by $\mathrm{I}^{2}$ test, and fixed models were selected if heterogeneity was not significant $\left(\mathrm{I}^{2}<50 \%\right)$, otherwise random models were selected. A funnel plot was performed to investigate the probability of small study effects. Meta-regression analysis and sensitivity analysis were performed by Stata 15 .

\section{Results}

\subsection{Eligible studies and assessment of bias risk}

A total of 1746 studies were initially identified, and 11 studies were included in the meta-analysis (Fig. 1). Two of these studies were English articles [11,12] and 9 of them were Chinese [13-21]. The total number of participants was 442 in the treatment group and 433 in the control group. Results of bias risk are shown in Fig. 2.

\subsection{Study characteristics}

As shown in Table 1, HBO therapy treatment was delivered in the hospital. The HBO parameters were as follows: $0.2 \mathrm{Mpa}$ were used in eight studies, and $0.23 \mathrm{Mpa}$ and $0.25 \mathrm{MPa}$ was used in two studies respectively. Five studies performed HBO therapy by oxygen mask while in six other studies this was performed by hyperbaric oxygen chamber. The single time of HBO therapy lasted from $60 \mathrm{~min}$ to $90 \mathrm{~min}$ with the treatment period ranging from 20 to 48 days. There were short intervals during the entire treatment.

\subsection{Primary outcomes}

\subsubsection{ASIA motor}

A total of 10 trials demonstrated motor function score with the ASIA motor scale. The random effect model was chosen for the analysis due to the high heterogeneity. Results demonstrated that HBO therapy significantly improved motor function (MD 15.84, 95\% CI 9.04 to $22.64, \mathrm{I}^{2}=87 \%$; Fig. 3a) and the funnel plot suggested there was no selective publication (Fig. 3b). The sensitivity analysis was also performed to explain the large heterogeneity, but the results demonstrated that there was no significant source of heterogeneity (Fig. S1).

\subsubsection{ASIA sensor}

A total of 6 trials reported the ASIA sensor score (total) while 4 trials reported light touch and needling respectively. The random effect model was chosen for

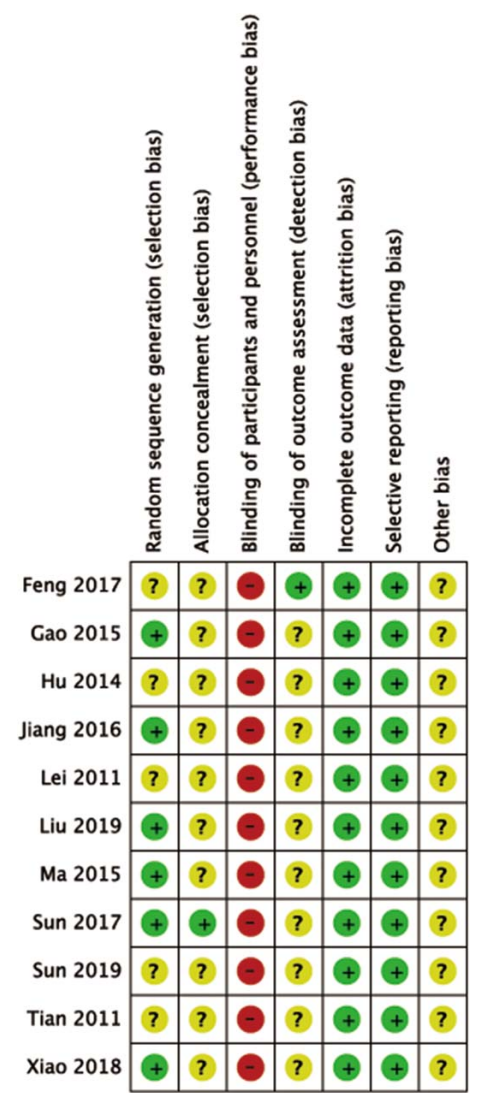

Fig. 2. The risks of bias assessment results of the Cochrane library assessment tool: (+) indicates low risk of bias, (?) means unclear, and (-) a high risk of bias on an item.

the analysis due to the high heterogeneity. Results of 6 trials suggested that $\mathrm{HBO}$ therapy statistically promoted sensory function (MD 66.30, 95\% CI 53.44 to 79.16 , $\mathrm{I}^{2}=95 \%$; Fig. 4a). For the other 4 trails, HBO therapy statistically increased the light touch score (MD 9.27, $95 \%$ CI 3.89 to $14.65, \mathrm{I}^{2}=91 \%$; Fig. $4 \mathrm{~b}$ ) and needling score (MD 10.01, 95\% CI 8.60 to $11.43, \mathrm{I}^{2}=95 \%$; Fig. 4c). Sensitivity analysis showed that the systematic exclusion of each study did not significantly affect the pooled results of the sensory score, but slightly affected the results of sensory score-light touch and needling (Fig. S2). The funnel plot suggested that there was no selective publication (Fig. S3).

\subsection{Secondary outcomes}

\subsubsection{MBI, HAMA and HAMD}

A total of 2 trials reported MBI and 2 reported HAMD and HAMA. The fixed effect model was chosen for the analysis of MBI and HAMA because there was no heterogeneity. HBO therapy was implicated in the 
Table 1

Characteristics of the included studies

\begin{tabular}{|c|c|c|c|c|c|}
\hline Studies & $\begin{array}{l}\text { Participants } \\
\text { (E/C) }\end{array}$ & Experimental group & Control group & Main outcomes & Follow-up \\
\hline Sun et al. 2019 & $41 / 38$ & $\begin{array}{l}\text { Chamber, 2.0ATA, } 60 \text { min, daily, } \\
30 \mathrm{~d}\end{array}$ & $\begin{array}{l}\text { Conventional drug treatment, } \\
\text { with (or without) surgical } \\
\text { treatment }\end{array}$ & $\begin{array}{l}\text { Plasma HMGB1 and NF- } \kappa \text { B, } \\
\text { ASIA motor scale, ASIA } \\
\text { sensory scale }\end{array}$ & 30 days \\
\hline Feng et al. 2017 & $20 / 20$ & $\begin{array}{l}\text { Oxygen mask, } 2.0 \text { ATA, } 60 \text { min, } \\
\text { daily, } 6 \text { times per week, } 8 \text { weeks }\end{array}$ & $\begin{array}{l}\text { Drugs and rehabilitation } \\
\text { therapy }\end{array}$ & $\begin{array}{l}\text { ASIA motor scale, ASIA } \\
\text { sensory scale, HAMD, } \\
\text { HAMA }\end{array}$ & 56 days \\
\hline Tian et al. 2011 & $31 / 31$ & $\begin{array}{l}\text { Chamber, } 0.2 \mathrm{MPa}(2.1 \mathrm{ATA}) \text {, } \\
60 \text { min, daily, } 10 \text { times/course, } \\
2 \text { courses }\end{array}$ & $\begin{array}{l}\text { Drugs and rehabilitation } \\
\text { therapy }\end{array}$ & $\begin{array}{l}\text { ASIA motor scale, ASIA } \\
\text { sensory scale }\end{array}$ & 20 days \\
\hline Sun et al. 2017 & $82 / 82$ & $\begin{array}{l}\text { Chamber, } 0.2 \mathrm{Mpa}, 60 \mathrm{~min} \text {, daily, } \\
10 \text { times/course, } 4 \text { courses }\end{array}$ & Routine surgical treatment & $\begin{array}{l}\text { ASIA motor scale, ASIA } \\
\text { sensory scale, MBI }\end{array}$ & 40 days \\
\hline Xiao et al. 2018 & $28 / 28$ & $\begin{array}{l}\text { Oxygen mask, } 90 \text { min, daily, } \\
10 \text { times/course, } 3 \text { courses }\end{array}$ & $\begin{array}{l}\text { Surgical treatment, drugs } \\
\text { and rehabilitation therapy }\end{array}$ & HAMD, HAMA & 30 days \\
\hline Jiang et al. 2016 & $43 / 43$ & $\begin{array}{l}\text { Oxygen mask, } 0.2 \mathrm{Mpa}, 60 \mathrm{~min} \text {, } \\
\text { daily, } 10 \text { times/course, } 2 \text { courses }\end{array}$ & Drugs & $\begin{array}{l}\text { ASIA motor scale, ASIA } \\
\text { sensory scale, Frankel motor } \\
\text { scale, Frankel sensory scale }\end{array}$ & 20 days \\
\hline Ma et al. 2015 & $64 / 64$ & $\begin{array}{l}\text { Chamber, } 0.2 \mathrm{Mpa}, 60 \mathrm{~min} \text {, daily, } \\
10 \text { times/course }\end{array}$ & $\begin{array}{l}\text { Surgical treatment, drugs } \\
\text { and rehabilitation therapy }\end{array}$ & $\begin{array}{l}\text { ASIA motor scale, ASIA } \\
\text { sensory scale }\end{array}$ & N/A \\
\hline Liu et al. 2019 & $21 / 21$ & $\begin{array}{l}\text { Oxygen mask, } 0.25 \mathrm{Mpa}, 90 \mathrm{~min} \text {, } \\
\text { daily, } 10 \text { times/course, } 3 \text { courses }\end{array}$ & $\begin{array}{l}\text { Surgical treatment, drugs } \\
\text { and rehabilitation therapy }\end{array}$ & $\begin{array}{l}\text { ASIA motor scale, ASIA } \\
\text { sensory scale }\end{array}$ & 30 days \\
\hline Gao et al. 2015 & $40 / 40$ & $\begin{array}{l}\text { Chamber, } 0.2 \mathrm{Mpa}, 80 \mathrm{~min} \text {, daily, } \\
10 \text { times/course, } 3 \text { courses }\end{array}$ & $\begin{array}{l}\text { Decompression and spinal } \\
\text { fixation }\end{array}$ & $\begin{array}{l}\text { ASIA motor scale, ASIA } \\
\text { sensory scale }\end{array}$ & 30 days \\
\hline Hu et al. 2014 & $40 / 40$ & $\begin{array}{l}\text { Oxygen mask, 2.0ATA, } 90 \text { min, } \\
\text { daily, } 10 \text { times/course, } 3 \text { courses }\end{array}$ & $\begin{array}{l}\text { Surgical treatment, drugs, } \\
\text { rehabilitation therapy and } \\
\text { methylprednisolone }\end{array}$ & $\begin{array}{l}\text { ASIA motor scale, ASIA } \\
\text { sensory scale }\end{array}$ & 30 days \\
\hline Lei et al. 2011 & $32 / 26$ & $\begin{array}{l}\text { Chamber, } 0.23 \mathrm{MPa}(2.3 \mathrm{ATA}) \text {, } \\
70 \mathrm{~min}, 10 \text { times/course, } 4 \text { courses }\end{array}$ & $\begin{array}{l}\text { Drugs and rehabilitation } \\
\text { therapy }\end{array}$ & $\begin{array}{l}\text { ASIA motor scale, ASIA } \\
\text { sensory scale, MBI }\end{array}$ & 40 days \\
\hline
\end{tabular}

E: Experimental group; C: Control group; Chamber: Hyperbaric oxygen chamber; MBI: Modified Barthel Index; HAMD: Hamilton Depression Scale; HAMA: Hamilton Anxiety Scale; MAS: Modified Ashworth Scale; BBS: Berg Balance Scale; FAC: Functional Ambulation Category Scale.

significant improvement of MBI (MD 13.80, 95\% CI 10.65 to $16.94, \mathrm{I}^{2}=0 \%$; Fig. $5 \mathrm{a}$ ). HBO therapy also decreased the HAMA (MD $-2.37,95 \% \mathrm{CI}-2.72$ to $-2.02, \mathrm{I}^{2}=0 \%$; Fig. 5b) and HAMD (MD $-3.74,95 \%$ CI -5.82 to $-1.65, \mathrm{I}^{2}=90 \%$; Fig. $5 \mathrm{c}$ ).

\section{Discussion}

To evaluate the role of $\mathrm{HBO}$ on the treatment of SCI, we performed a systematic review of RCTs and found that $\mathrm{HBO}$ could improve the ASIA motor score, ASIA sensory score, MBI score, HAMA and HAMD. Our study suggested that HBO may positively affect the motor function and sensory function, improve the ADL, and decrease depression and anxiety of patients with SCI. Although patients with SCI in clinical practice are heterogeneous and thus may respond differently to HBO therapy, the results demonstrated that HBO therapy statistically promoted the motor and sensory function as well as the ADL.

HBO therapy shows encouraging neuroprotective effects in previous experimental research, however, the mechanism of $\mathrm{HBO}$ on SCI was unclear. The major rea- sons for the intractability of SCI involve the edema of nerve cells, lipid peroxide and oxygen free radicals, resulting in a series of reaction such as obstacle of spinal marrow micro loop, activation of neural protease, cytotoxicity and apoptosis $[13,14]$. Consequent secondary injuries block the regeneration of nerve fibers and axon so that SCI becomes 'irreversible' with a range of motor and sensory impairments $[2,15]$. Treatment of SCI should focus on inhibiting inflammation, reducing cytotoxicity and apoptosis, and promoting the regeneration of nerve fibers and axon [16]. Firstly, HBO therapy could decrease apoptosis after traumatic SCI by downregulating the hypoxia-induced iNOS gene expression, inflammatory cytokines such as interleukin IL-1 $\beta$ and tumor necrosis factor (TNF- $\alpha$ ) $[17,18]$, apoptosis-associated speck-like protein containing a CARD (ASC), and ER-stress-induced apoptotic pathway. Secondly, HBO therapy could regulate oxidative stress. HBO may decrease the level of lipid peroxidation and this mechanism refers to several makers, malondialdehyde (MDA) [19], catalase and superoxide dismutase, heat shock protein (HSP32) [20], and nuclear factor erythroid 2-related factor 2 (Nrf2) [21]. Thirdly, HBO therapy could reduce inflammation through han- 
a

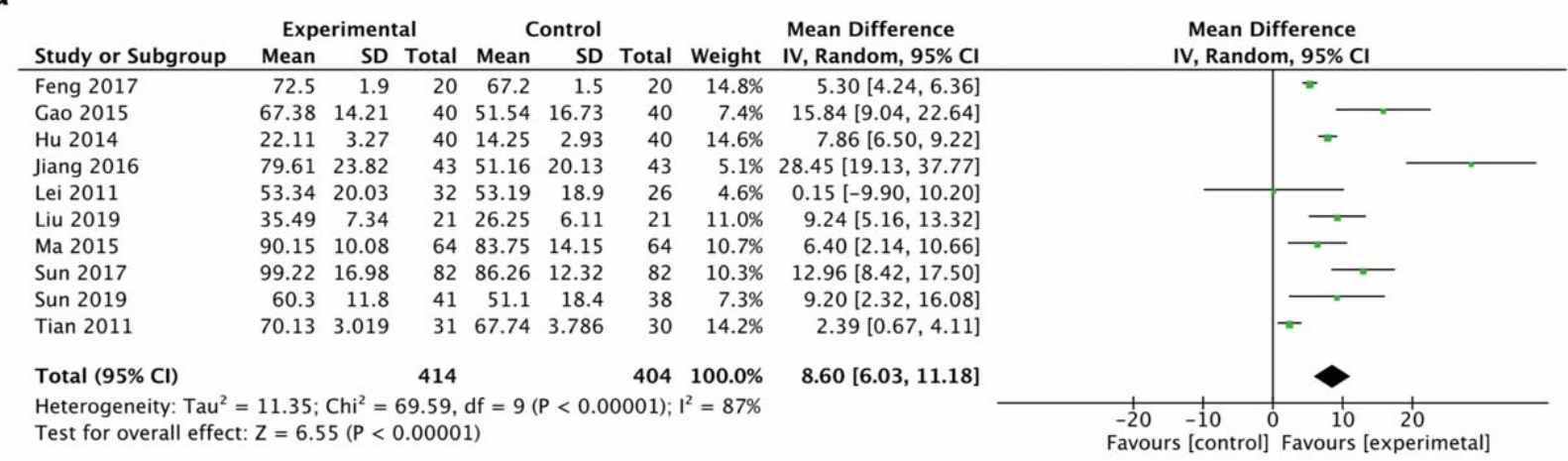

b

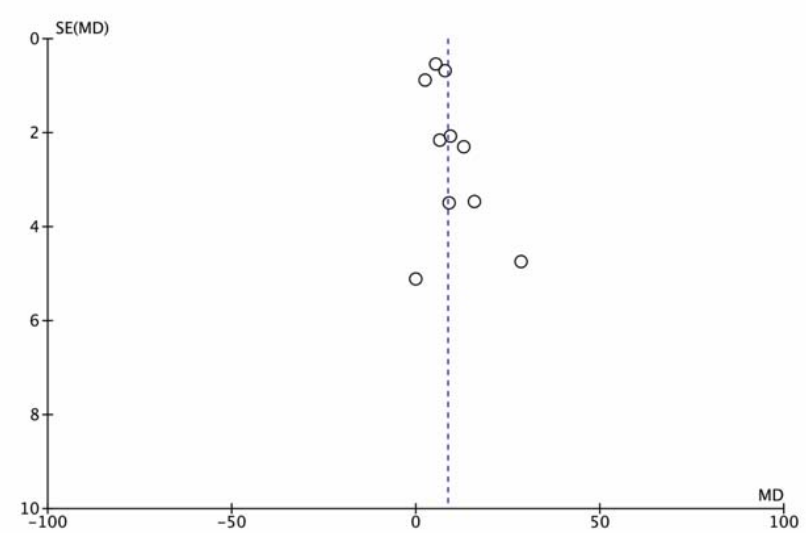

Fig. 3. Forest plot (a) and funnel plot (b) of ASIA motor score of the included studies comparing the effects of the HBO and control groups.

dling the balance of anti-inflammatory M2 phenotype and inflammatory M1 phenotype [22], declining NALP3 inflammasome [23], adjusting MMP-2 and MMP-9 [24], governing the expression of high-mobility group protein B1 (HMGB1) [25,26], and regulating gap junctions [27]. Fourthly, HBO therapy could promote angiogenesis which may be associated with vascular endothelial growth factor (VEGF) [28]. HBO therapy could also reduce water access into the spinal cord by downregulating the expression of aquaporin 4 (AQP4), reduce metalloproteinases, and ultimately decrease the spinal cord edema. Autophagy upregulation induced by $\mathrm{HBO}$ therapy could encourage repair and protection after SCI [29].

Although SCI in clinical practice is heterogeneous and thus may respond differently to HBO therapy, the results demonstrated that HBO therapy statistically promoted the motor and sensory function as well as ADL. The mechanism may be that HBO therapy could regulate microcirculation, improve blood oxygen tension, and increase the content of physically dissolved oxygen in the blood, thus enabling the body to complete cell metabolism with sufficient oxygen support [30] and relieve spinal edema. HBO therapy could also prevent nerve cells from apoptosis after SCI, regulate oxidative stress and lipid peroxidation, and ultimately boost the recovery of nerve function. Based on the above mechanism, the earlier hyperbaric oxygen therapy is applied, the better the recovery of SCI will be.

However, we did not identify the heterogeneity source after meta-regression for ASIA motor score and ASIA sensory score by methods of HBO therapy, treatment duration and treatment course (data not shown). Sensitivity analysis showed that systematic exclusion of each study did not significantly affect the pooled results (Fig. S1). For sensory score-light touch and needling, studies by Sun et al. and Tian et al. indicate potential heterogeneity source (Fig. S1). Because these studies had difficulty in being divided into subgroups, we conjectured that high heterogeneity may be implicated in the divergent severity of SCI.

Due to sudden changes of physiological condition and social status, paralysis could not be fully cured, the gap between expectations and clinical treatment effect, patients with SCI take unbearable psychological pressure and are prone to generating a series of non- 
a

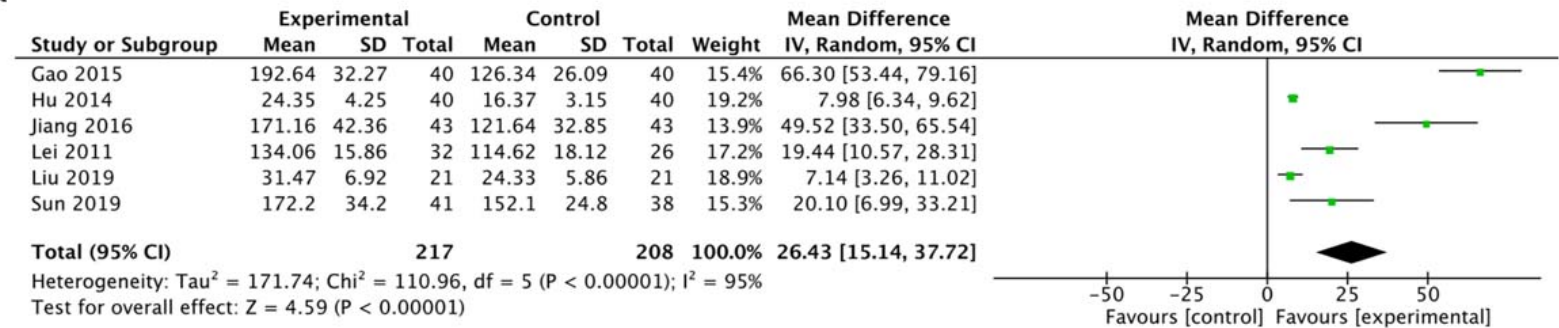

b

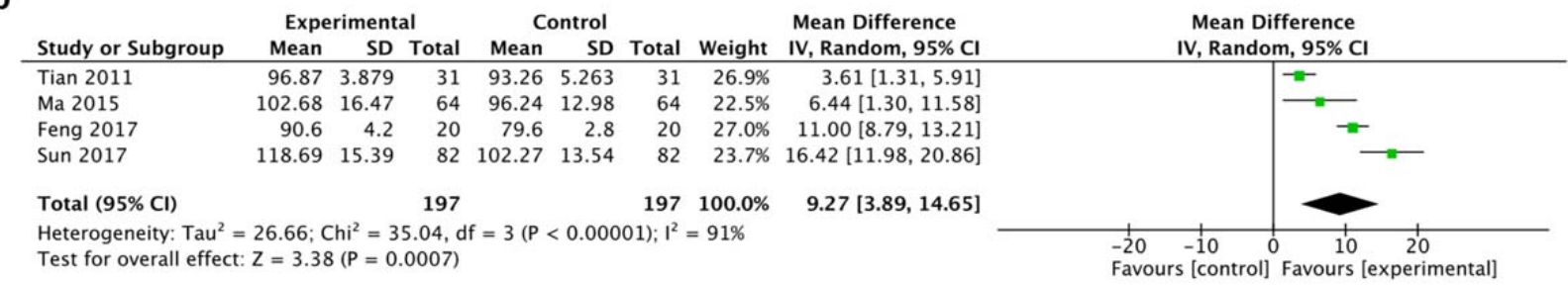

C

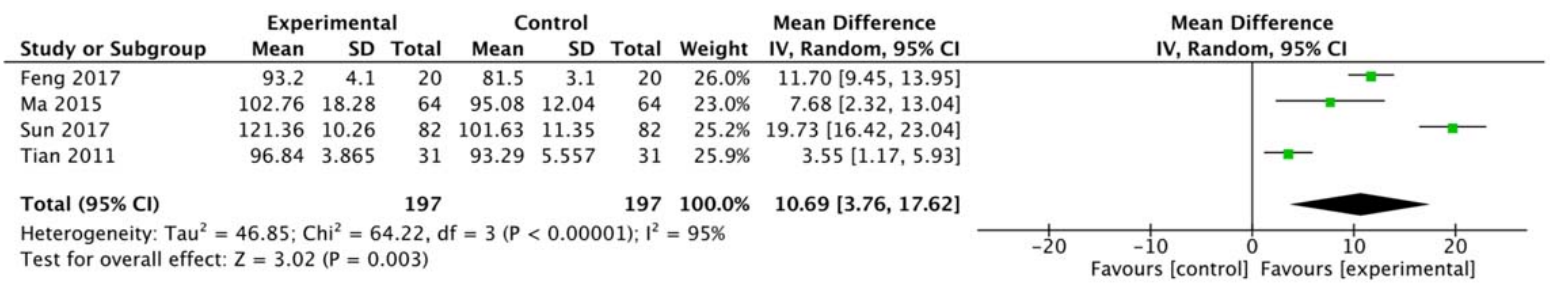

Fig. 4. Forest plot of ASIA sensory score (a), ASIA sensory light touch score (b) and ASIA needling score (c) of the included studies comparing the effects of the HBO and control groups.

specific psychological reactions, such as anxiety, depression and other psychological emotional problems of a different level [31]. Approximately $60 \%$ of SCI patients suffer from depression [32]. HBO can relieve anxiety and depression in patients and this effect may benefit a virtuous cycle, in which patients are more willing to cooperate with the rehabilitation treatment after their functions have restored utilizing HBO and their depression or anxiety have also been alleviated.

Due to the small sample size included in this study, more high-quality and large-sample size RCTs are necessary to confirm the results demonstrated in the present study. Moreover, the results of all studies were positive, indicating a possible publication bias. Besides, HBO therapy treatment duration and treatment course had some differences, and this might be one of the reasons why the present study did not determine a consistent treatment parameter. In short, current clinical treatments only achieve limited efficacy, so the prognosis for patients with SCI remains poor. Restoration of the mo- tor functions after SCI remains an elusive goal. Over the years, many studies have shown that HBO therapy possesses desirable effects on the tissue edema, local inflammation, secondary injury and functional recovery for SCI. Therefore, HBO therapy may be useful for clinical treatment as a safe, promising and effective treatment.

\subsection{Limitations}

Our study has some limitations. First, we did not identify the heterogeneity source after meta-regression for ASIA motor score and ASIA sensory score by methods of HBO therapy, treatment duration and treatment course (data not shown). Sensitivity analysis showed that systematic exclusion of each study did not significantly affect the pooled results (Fig. S1). For sensory score-light touch and needling, the studies by Sun et al. and Tian et al. indicated the potential heterogeneity source (Fig. S1). Because these studies had difficulty 
a

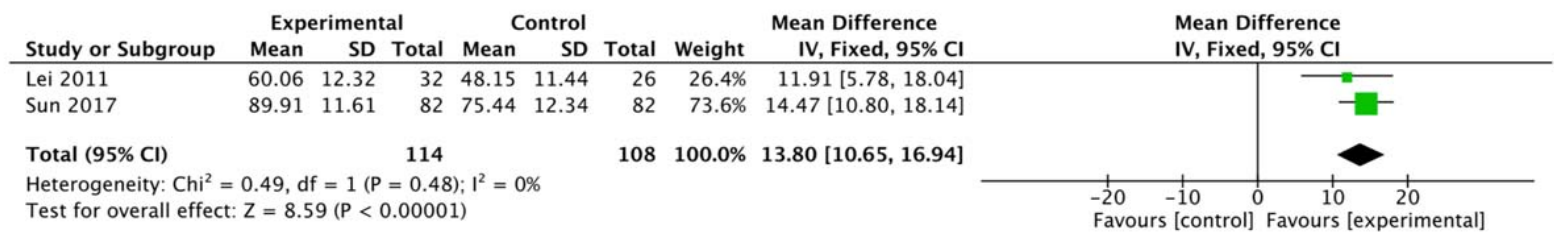

b

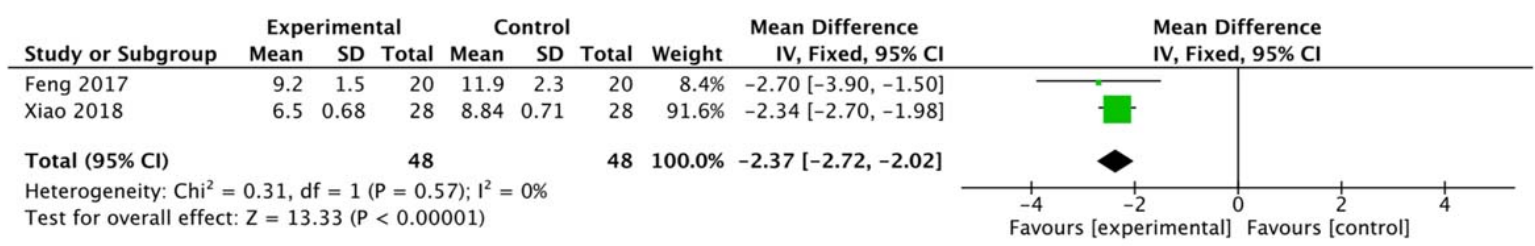

C

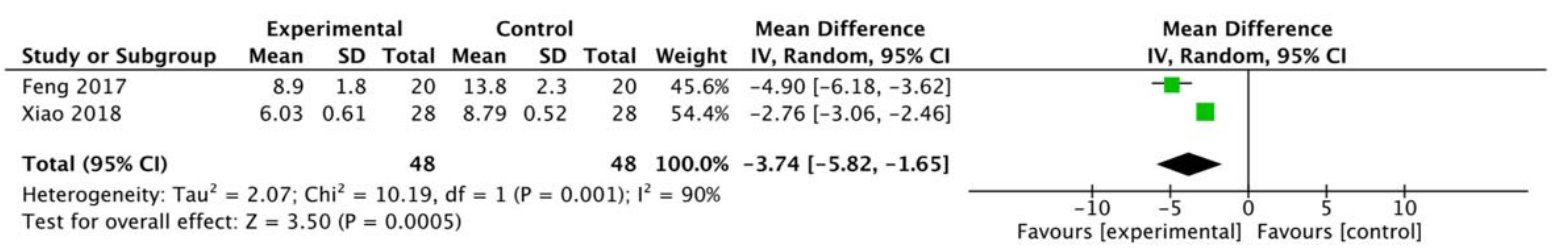

Fig. 5. Forest plot of MBI (a), HAMA (b) and HAMD (c)of the included studies comparing the effects of the HBO and control groups.

in dividing subgroups, we conjectured that high heterogeneity may be implicated in the divergent severity of SCI. Second, the credibility of the results should be taken with caution because the number of studies was only two, so more RCTs are needed to determine HBO's performance in anxiety and depression.

\section{Acknowledgments}

All authors have read and approved of the manuscript. This work was supported by the National Natural Science Foundation of China (Grant No. 81572231). The funder had no role in the study design, data collection and analysis, decision to publish, or preparation of the manuscript.

\section{Conflict of interest}

The authors declare that they have no competing interests.

\section{Supplementary data}

The supplementary files are available to download from http://dx.doi.org/10.3233/BMR-200157.

\section{References}

[1] Singh A, Tetreault L, Kalsi-Ryan S, Nouri A, Fehlings MG. Global prevalence and incidence of traumatic spinal cord injury. Clin Epidemiol. 2014; 6: 309-31.

[2] Assinck P, Duncan GJ, Hilton BJ, Plemel JR, Tetzlaff W. Cell transplantation therapy for spinal cord injury. Nature Neuroscience. 2017; 20(5): 637-47.

[3] Chehensse C, Bahrami S, Denys P, Clement P, Bernabe J, Giuliano $\mathrm{F}$. The spinal control of ejaculation revisited: a systematic review and meta-analysis of anejaculation in spinal cord injured patients. Hum Reprod Update. 2013; 19(5): 507-26.

[4] Liu JM, Long XH, Zhou Y, Peng HW, Liu ZL, Huang SH. Is urgent decompression superior to delayed surgery for traumatic spinal cord injury? A meta-analysis. World Neurosurg. 2016; 87: 124-31.

[5] Holbach KH, Wassmann H, Linke D. The use of hyperbaric oxygenation in the treatment of spinal cord lesions. European neurology. 1977; 16(1-6): 213-21.

[6] Zurolo E, Iyer A, Maroso M, Carbonell C, Anink JJ, Ravizza $\mathrm{T}$, et al. Activation of toll-like receptor, RAGE and HMGB1 signalling in malformations of cortical development. Brain. 2011; 134(Pt 4): 1015-32.

[7] Li X, Jin Q, Yao Q, Xu B, Li Z, Tu C. Quercetin attenuates the activation of hepatic stellate cells and liver fibrosis in mice through modulation of HMGB1-TLR2/4-NF-kappaB signaling pathways. Toxicol Lett. 2016; 261: 1-12.

[8] Dayan K, Keser A, Konyalioglu S, Erturk M, Aydin F, Sengul $\mathrm{G}$, et al. The effect of hyperbaric oxygen on neuroregeneration following acute thoracic spinal cord injury. Life sciences. 2012; 90(9-10): 360-4.

[9] Patel NP, Huang JH. Hyperbaric oxygen therapy of spinal cord injury. Med Gas Res. 2017; 7(2): 133-43. 
[10] Moher D, Liberati A, Tetzlaff J, Altman DG, Group P. Preferred reporting items for systematic reviews and metaanalyses: the PRISMA statement. PLoS Med. 2009; 6(7): e1000097.

[11] Sun L, Zhao L, Li P, Liu X, Liang F, Jiang Y, et al. Effect of hyperbaric oxygen therapy on HMGB1/NF-kappaB expression and prognosis of acute spinal cord injury: a randomized clinical trial. Neuroscience Letters. 2019; 692: 47-52.

[12] Feng JJ, Li YH. Effects of hyperbaric oxygen therapy on depression and anxiety in the patients with incomplete spinal cord injury (a STROBE-compliant article). Medicine. 2017; 96(29): e7334.

[13] Lihua X, Qibiao W, Huangyi L. Effects of hyperbaric oxygen therapy on depression and anxiety in patients with incomplete spinal cord injury. Journal of Qiqihar Medical University. 2018; 39(22): 2633-2634

[14] Hongcheng T, Yongcheng J. Study of hyperbaric oxygen's adjunctive therapeutic effects on function recovery in spinal cord injury patient. Modern Medicine Journal of China. 2011; 13(9): 11-12.

[15] Qing S, Jian-feng B, Yu-lan A, Hui L, Jun M. Hyperbaric oxygen therapy and comprehensive orthopedic treatment for incomplete traumatic spinal cord injury on the qinghai-tibet plateau: study protocol for an open-label randomized controlled clinical trial. Chinese Journal of Tissue Engineering Research. 2017; 21(20): 3269-3274.

[16] Xianfeng J, Fengwu T, Xuyi C, Sai Z. Effect of hyperbaric oxygen therapy on surgical treatment of traumatic cervical spine and spinal cord injury. Chinese Journal of Practical Nervous Diseases. 2016; 19(8): 87-88.

[17] Jun M, Zhong G, Yong X. Study on hyperbaric oxygen therapy for acute traumatic spinal cord injury in plateau area. Journal of High Altitude Medicine. 2015; 25(3): 20-21.

[18] Lanxiang H, Zhujun X. Effect observation of hyperbaric oxygen combined with methylprednisolone in the treatment of acute spinal cord injury. China Health Care\&Nutrition. 2014; 24(3): 1242-3.

[19] Zhiwei L, Guobiao Y. Analysis of combined hyperbaric oxygen therapy for acute spinal cord injury. The Channel of Medical. 2019; 31(5): 192-193.

[20] Zhangquan G, Xiaoqiu W, Lixiang L, Renjian L, Zhen G, Qi $\mathrm{C}$, et al. Effect analysis of hyperbaric oxygen in the treatment of traumatic spinal cord injury. Chinese and Foreign Medical Research. 2015; 13(11): 113-114.
[21] Beiping L, Ganxiang L, Zhengchao H. Eficacy of early hyperbaric oxygen therapyin acute spinal cord injury. J Clin Res. 2011; 28(3): 472-474.

[22] Geng CK, Cao HH, Ying X, Zhang HT, Yu HL. The effects of hyperbaric oxygen on macrophage polarization after rat spinal cord injury. Brain Res. 2015; 1606: 68-76.

[23] Liang F, Li C, Gao C, Li Z, Yang J, Liu X, et al. Effects of hyperbaric oxygen therapy on NACHT domain-leucinerich-repeat- and pyrin domain-containing protein 3 inflammasome expression in rats following spinal cord injury. Molecular Medicine Reports. 2015; 11(6): 4650-6.

[24] Yang J, Wang G, Gao C, Shao G, Kang N. Effects of hyperbaric oxygen on MMP-2 and MMP-9 expression and spinal cord edema after spinal cord injury. Life Sci. 2013; 93(25-26): 1033-8.

[25] Yang J, Liu X, Zhou Y, Wang G, Gao C, Su Q. Hyperbaric oxygen alleviates experimental (spinal cord) injury by downregulating HMGB1/NF-kappaB expression. Spine (Phila Pa 1976). 2013; 38(26): E1641-8.

[26] Tan J, Zhang F, Liang F, Wang Y, Li Z, Yang J, et al. Protective effects of hyperbaric oxygen treatment against spinal cord injury in rats via toll-like receptor 2/nuclear factor-kappaB signaling. Int J Clin Exp Pathol. 2014; 7(5): 1911-9.

[27] O'Carroll SJ, Alkadhi M, Nicholson LF, Green CR. Connexin 43 mimetic peptides reduce swelling, astrogliosis, and neuronal cell death after spinal cord injury. Cell Commun Adhes. 2008; 15(1): 27-42.

[28] Widenfalk J, Lipson A, Jubran M, Hofstetter C, Ebendal T, Cao Y, et al. Vascular endothelial growth factor improves functional outcome and decreases secondary degeneration in experimental spinal cord contusion injury. Neuroscience. 2003; 120(4): 951-60.

[29] Sun Y, Liu D, Su P, Lin F, Tang Q. Changes in autophagy in rats after spinal cord injury and the effect of hyperbaric oxygen on autophagy. Neurosci Lett. 2016; 618: 139-45.

[30] Webb AA, Ngan S, Fowler JD. Spinal cord injury i: a synopsis of the basic science. Can Vet J. 2010; 51(5): 485-92.

[31] Harrington P. Prevention of surgical site infection. Nurs Stand. 2014; 28(48): 50-8

[32] Shin JC, Goo HR, Yu SJ, Kim DH, Yoon SY. Depression and quality of life in patients within the first 6 months after the spinal cord injury. Ann Rehabil Med. 2012; 36(1): 119-25. 